\title{
Engajamentos além do curtir: a pirâmide da pedagogia hacker
}

\author{
Karina Moreira Menezes \\ FACED | UFBA e Raul HC \\ Salvador, Brasil \\ orcid.org/0000-0002-0524-2848
}

\author{
Nelson De Luca Pretto \\ FACED | UFBA \\ Salvador, Brasil \\ orcid.org/0000-0001-8152-8963
}

\begin{abstract}
The hacker pedagogy pyramid (P2H) is the result of a qualitative research using the Constructivist grounded theory to investigate the educational phenomenon within Brazilian community experimental laboratories of technology also called hackerspaces. $\mathrm{P} 2 \mathrm{H}$ is a type of multi-faceted engagement pedagogy, with four specific and interrelational faces: one technique, one affective, one idea and one activist. The four faces are types of motivations that form a threedimensional pyramid in which hacker pedagogy in hackerspaces is politically and ideologically structured. Engagement is understood as a decision about oneself and, at the same time, action on other people being unthinkable to keep the hacker space alive in a manner consistent with its principles and contradictions.
\end{abstract}

Resumo - A pirâmide da pedagogia hacker $(\mathrm{P} 2 \mathrm{H})$ é resultado de uma pesquisa qualitativa tendo como método a Teoria Fundamendada (TEF) com o ojetivo de investigar o fenômeno educativo dentro de laboratórios comunitários experimentais de tecnologia brasileiros também chamados de hackerspaces. A P2H é um tipo de pedagogia de engajamento multifacetado, com quatro faces específicas e inter-relacionais: uma técnica, uma afetiva, uma ideária e uma ativista. As quatro faces são tipos de motivações que formam uma pirâmide tridimensional na qual a pedagogia hacker em hackerspaces se estrutura política e ideologicamente. $O$ engajamento é compreendido como decisão sobre si e ao mesmo tempo, ação sobre outrs pessoas sendo indipensável para manter vivo o espaço hacker de forma coerente com seus princípios e contradições.

Palavras-chave-1. Educaçao Hacker; 2. Hackerspaces; 3 . Movimento hacker

\section{INTRODUÇÃO}

Ainda hoje a palavra hacker desperta um imaginário negativo relacionado a criminosos do mundo digital. Contudo, originariamente, a palavra hacker vem do inglês “to hacker” e significa entalhar, esculpir madeira. Seu significado foi popularizado entre jovens e professores do Massachusetts Institute of Tecnology (MIT), para se referir a pessoas que fazem "hacks" ou seja, apresentam ideias talentosas, criativas, com espírito lúdico e inovador. Portanto, ao nos referirmos aos hackers, não falamos de criminosos do mundo digital, nos referimos a pessoas e comunidades que usam que usam seu conhecimento e talento com tecnologias para resolver desafios de forma criativa, e ainda compartilhar aquilo que fazem e propondo soluções práticas para a vida real. Portanto, a cultura hacker, em sua origem, está relacionada a essas pessoas, atuantes em diferentes áreas do conhecimento, não apenas nas áreas da computação ao informática. A cultura hacker defende a liberdade, a privacidade, o compartilhamento de informação, o fortalecimento comunitário. Se hoje temos uma internet que o conecta o mundo todo, de diferentes formas, permitindo que celular se conecte com computador, com micro-ondas, com a televisão e até com cafeteiras, temos que agradecer a hackers. Conforme sistematizado por diferentes autores, a ética dos hackers defende que o conhecimento - e as formas de acessá-lo - deve ser para todas as pessoas (MENEZES, 2018) ${ }^{1}$

Há um movimento de positivação da palavra hacker encampado por ativistas e estudiosos e estes enfatizam aspectos considerados comuns a práticas sociais desse grupo como o compartilhamento, a colaboração e a abertura. Ao londo dos ultimos sessenta anos, autores dedicados a sistematizar a ética e a cultura hacker - Eric Raymond, Pekka Himanem, Steven Levy, Gabriela Coleman - dentre outros destacam a importância desses sujeitos para o desenvolvimento científico e tecnológico da sociedade contemporânea e trazem elementos que contribuem para se repensar a produção de conhecimento em diversas áreas da vida humana, dentre elas, a educação.

Nos dedicamos a investigar a relação entre hackers com a educação principalmente porque, na atualidade, a presença de hackers tem sido cada vez mais evidenciada e necessária. As tecnologias em rede reconfiguram nossos modos de vida, pois o mundo é conectado por redes informacionais (CASTELLS, 2001) ${ }^{2}$ estruturadas por tecnologias de informação e comunicação (TIC) que 
condicionam a organização socioeconômica do nosso tempo, estruturando e modificando a comunicação, a cultura e os espaços de poder. Com a informatização do cotidiano (CAZELOTO, 2008) $)^{3}$ naturalizamos a convivência com as máquinas informacionais de tal modo que poucas pessoas se preocupam em saber como e por quê os aparelhos funcionam. "Dessa forma, perde-se de vista que tecnologias são produtos da intelecção humana, portanto, são falíveis, incompletas e condicionadas a fatores econômicos” (MENEZES, 2018:32) ${ }^{1}$.

A banalização e a naturalização das relações humanas mediadas pelas máquinas ocorre sem investimento na formação das pessoas para compreender e lidar com as tecnologias digitais, isso mantém concepções instrumentais que tendem a naturalizar estruturas de dominação através delas. Grandes corporações tecnológicas têm influenciado a criação de monopólios comunicacionais e de produção de bens digitais que não são acessíveis para maior parte da população mundial. Em dimensão global, o desenvolvimento tecnológico se faz em detrimento de outros aspectos da vida social e ambiental, produzindo cenários de paradoxos, desigualdades e exclusões que se expandem pelo mundo.

Diante desse cenário, observamos a emergência de movimentos sociais descentralizados e informais que se colocam na contramão da cultura hegemônica, buscando outras formas de produção cultural e de sociabilidade que vão além do ciberespaço e da cibercultura propondo outros olhares e outras formas de desenvolvimento sócioeconômico. O movimento MetaReciclagem, iniciado em 2002, a partir de uma lista de discussão chamada de Projeto Metá:Fora, na qual se debatia comunicação, internet, filosofia e cibercultura, constituiu-se como um projeto aberto, ancorado nos princípios do software livre (DIAMANTAS, 2013) ${ }^{4}$ e envolveu ativistas, acadêmicos, comunicadores, programadores e pessoas em torno de projetos nas áreas de educação, arte, tecnologia. O MetaReciclagem foi precursor na crítica ao excesso de lixo tecnológico e na defesa da engenharia reversa como forma de aprendizagem e de sustentabilidade econômica e social no Brasil. Esse movimento, iniciado por listas de discussão, a criação de um dos primeiros espaços hackers do Brasil, o Bailux, cujo nome é junção das palavras Bahia + Linux, e foi fundado no distrito Arraial d'Ajuda, em Porto Seguro no estado da Bahia/Brasil.
Um hackerspace ou espaço hacker é um tipo um laboratório coletivo experimental de tecnologias, autogestionário, mantido por pessoas que se orientam por princípios e valores da cultura hacker, independemente de sua formação profissional ou acadêmica. Diferentemente do que se poderia pensar, um hackerspace é vivido na presencialidade não bastando suas redes virtuais, mesmo que essas tenham enorme importância para a organização e transparência das atividades realizadas.

\section{A. Objetivo e Metodologia}

Com o objetivo de analisar o fenômeno educativo em hackerspaces brasileiros para sistematizar elementos da pedagogia desses espaços, realizamos uma pesquisa qualitativa orientada à teoria fundamentada (TEF) na perspectiva de Kathy Charmaz (2009:24) ${ }^{5}$ que defende envolvimento simultâneo na coleta e na análise de dados para construção de "um retrato interpretativo do mundo estudado”. A metodologia envolveu pesquisa-participante em um espaço hacker, entrevistas por e-mail e em eventos presenciais de tecnologias, além da aplicação de um questionário online com questões dissertativas. A amostra contemplou grupos de cinco regiões do Brasil e teve contato com integrantes de cerca de vinte e três diferentes laboratórios hackers brasileiros. Coerentemente com a perspectiva de ciência aberta, além da novidade do tema e com a intenção de contribuir para disseminar informações acerca do movimento de hackerspaces no Brasil uma parte das entrevistas sistematizadas através de memorandos, foram adaptadas em forma de microartigos e publicados pela revista AREDE Educa nos meses de Novembro e Dezembro de 2016 categoria "Especial Hackerclubs" (Disponível em http://www.arede.inf.br/category/especialhackerclubs/).

\section{CONSTRUTOS DA INVESTIGAÇÃO}

Dentre as formas organizativas encontradas a partir dessa investigação, encontramos locais mantidos por grupos de amigos através de ocupação ou pagamento de aluguel, parcerias com instituições públicas ou particulares, parcerias com instituições culturais, coworkings, dentre outros, tendo em comum o compartilhamento da infraestrutura, 
ferramentas e troca de informações e de práticas especializadas em diferentes áreas do conhecimento. O estudo evidenciou que a criação e manutenção de um hackerspace demanda tempo e articulações que dependem de muitos fatores, como por exemplo, a sinergia entre as pessoas envolvidas, a escolha de um nom, de um local, a preparação de uma infraestrutura física e a manutenção do local, com as despesas mensais, a limpeza e a realização de encontros presenciais, dentre outros. Este conjunto de ações exige participação e engajamento das pessoas e por isso, não basta apenas curtir visto ser preciso fomentar processos educativos nestes espaços e disseminar o sentido originário do se hacker.

A construção de uma visão positiva do movimento hacker acontece numa zona conflituosa de contradições e burlas que questionam diversas formas de dominação e de desigualdades sociais. Isso coloca em evidência a necessidade de nos debruçarmos sobre questões atuais e urgentes como o direito à informação e ao conhecimento para todos, o desejo de aprender e o apelo para se construir processos de gestão e de aprendizagem colaborativos tendo as tecnologias como componente essencial da sociedade.

O movimento mundial de hackerspaces teve início com o Caos Club Computer (CCC) de Berlim/Alemanha fundado em 12 de setembro de 1981 após conferência tecnológica CoCon que acontecia em meio às mudanças políticas que levaram à queda do muro de Berlim. Buscavase um espaço seguro no qual hackers pudessem estar juntos e no qual "a descentralização e a falta de hierarquia podem ser a força que faz o clube resistir a todas as tendências de se dissolver e se desintegrar, sendo ainda uma comunidade próspera e crescente de indivíduos e que regularmente consegue se reinventar" (ASTERA E PETTI, 2008:06) ${ }^{6} \mathrm{O}$ conceito do CCC foi se disseminando e inspirou novos grupos dentro e fora da Alemanha, como a criação de grandes hackerspaces estadunidenses como o Noisebridge em São Francisco/Califórnia-EUA. Podemos afirmar que

participar de um hackerspace é como ser membro de um clube com sedes em diferentes locais do mundo. Usualmente, quando um integrante viaja, tende a buscar os hackerspaces existentes naquele lugar. Isso se dá, não por mera curiosidade, mas pelo senso de pertencimento que vai sendo construído através da ideia de que os mesmos princípios são compartilhados. (MENEZES, 2018)
A troca de informações e conhecimentos entre participantes de hackerspaces influencia a expansão do movimento e torna patente as interações possibilitadas pela abertura e disponibilidade de integrantes de hackerspaces em conhecer e contribuir com outros espaços. No Brasil, Juca, integrante do Garoa Hacker Club, foi conhecer o NYC Resistor em Nova York para desenvolver o projeto de um fliperama com tecnologias abertas e isso fortaleceu o propósito de criação do hackerclub paulistano. O Garoa Hacker Club, por sua vez, recebeu a visita de integrantes de outros hackerspaces como o Matehackers, MariaLab, Tarrafa, Hackerspace Salvador, Raul Hacker Club, HapHacks e compartilhou sua forma de funcionamento. Man Filho do Raul Hacker Club, visitou vários espaços hackers antes de ativamente participar da fundação do Raul Hacker Club. Há figuras notórias desse movimento, como Anchises, também integrante do Garoa Hacker Club, reconhecido como grande estimulador de hackerspaces, tendo visitado vários deles.

A formação dessas redes dentro do movimento é um dos aspectos essenciais na constituição dos espaços hackers, pois concorrem para unificar princípios globais ao mesmo tempo em que acolhem demandas e valores locais. Segundo Grigolo Júnior apud MENEZES (2018) ${ }^{1}$

[...] um hackerspace é uma resposta local, dentro de uma cultura local, a uma necessidade local. É pensar globalmente, mas agir localmente. Esse é o hackerspace. Hackerspaces não são iguais nem na mesma cidade, quanto mais em países distintos ou em continentes distintos. (GRIGOLO JÚNIOR, dados de pesquisa)

Ao identificarmos práticas educativas comuns a esses espaços e conhecer as respostas de participantes de hackerspaces sobre suas motivações, percebemos a indissociabilidade entre a educação e a manutenção do espaço hacker, o que nos levou a sistematizar uma pedagogia de engajamento multifacetado por motivações técnicas, idearias, afetivas e ativistas. A metáfora da pirâmide de bases intercambiáveis que caracteriza essa pedagogia hacker nos mostra que o engajamento em hackerspaces é muito mais do que "curtir”: é estar presente e se realmente se importar com o que acontece ali.

Algo comum aos hackerspaces brasileiros está na presença voluntária e na organização de projetos que é o motor das atividades realizadas em um espaço hacker, mesmo que esses projetos não sejam sistematizados 
claramente. Um projeto pode ser uma necessidade do espaço, seja a compra de uma geladeira ou um interesse de uma pessoas ou um grupo, como o desenvolvimento de um protótipo de robótica ou estudos na área de segurança. Em torno dos projetos é que nascem diferentes agrupamentos dentro do espaço hacker. Há grupos perenes, como aqueles que cuidam da manutenção e do desenvolvimento do espaço e há grupos temporários, que se desfazem mais rapidamente, após uma atividade de hacking, por exemplo. E em todas essas situações, há algum tipo de aprendizagem, seja ela intuitiva ou intencional.

Em hackerspaces, os integrantes tem que compartilhar o espaço físico, ferramentas, responsabilidades, ideias e conhecimentos de forma voluntária. Dentre as formas mais comuns utilizadas para a socialização de conhecimentos - aos quais chamamos prátics educativas - encontramos grupos de estudos, oficinas, palestras, conversas e rodas de conversa. Existem também alguma recorrência de práticas que são comuns à área de tecnologia e segurança da informação tais como hackathons, CTF e dojos, nos quais os saberes técnicos são construídos de forma prática pelos participantes, através da convivência entre pessoas com diferentes níveis de conhecimento. Encontramos momentos dedicados à atividades completamente lúdicas, como cinema, jogos de tabuleiro, produção de bebidas. Contudo, cabe ressaltar que desde um grupo de estudos à uma jogatina, todas essas situações tem um componente lúdico pois o desejo de diversão e a horizontalidade nas relações de ensino tornam os momentos prazerosos, afetivos e desafiadores para os membros responsáveis pela atividades que, de modo geral, ainda se precupam em manter a abertura do espaço, sem deixar de ser seguro e privativo.

Por isso, a aprendizagem técnica é importante, mas não é a centralidade na vida de um hackerspace, afinal manter o espaço em funcionamento é igualmente importante e tudo isso está interligado. Por isso, nem sempre um hackerspace é tão bonito, agradável ou equipado quanto um laboratório tecnológico de última geração, mas é ser um local instigante e desafiador para seus integrantes, "pois ao mesmo tempo, é o local no qual se encontra parceiros para fazer proposições loucas, para ‘aprenderensinando’ e ainda lidar com problemas práticos como fazer um vaquinha para comprar uma ferramenta nova ou pagar a conta de luz" (MENEZES, 2018) ${ }^{1}$.
Portanto, os processos educativos em hackerspaces ocorrem também para responder à necessidade de manutenção de sua própria existência como espaço físico. É nesse sentido que é preciso que seus integrantes se preocupem em incluir e acolher mais pessoas em torno de sua causa.

Acolher é incluir não se reume a manter o local aberto para receber visitas. A visita de uma pessoa a um espaço hacker não é suficiente para definir sua permanência. Cientes disso, encontramos hackerspaces que promovem ações para equalizar o acesso e a participação das pessoas, seja do ponto de vista financeiro quanto da aprendizagem. Na dimensão financeira, é comum que as atividades sejam gratuitas pois o espaço já é bancado por uma taxa mensal, paga pelos integrantes mais atuantes (membros ou sócios) ou por apoiadores externos. Alguns coletivos usam da chamada "hacker-hora": quanto mais a pessoa investe seu tempo em projetos do espaço hacker, mais ela acumula hacker-horas como contrapartida para se tornar sócio/membro e usufruir de benefícios diferenciados.

Quanto à aprendizagem, alguns grupos promovem oficinas e encontros dedicados a ensinar conteúdos básicos da área de tecnologias e assim aproximam as pessoas alinhando os saberes e as linguagens locais, tornando o local mais inclusivo para seus participantes. A inclusão é uma relação que se inicia com o acolhimento. Não basta abrir as portas, se não houver uma aceitação inicial daquele que é diferente, mas que pode partilhar coisas em comum. Compartilhar da mesma cultura, compreender a linguagem daquele lugar e das pessoas que por ali circulam é importante para o engajamento e permanência. Se um indivíduo ou um grupo não conseguem encontrar ou construir algo comum entre si e aquele espaço, dificilmente irão permanecer, pois não haverá base para se construir nenhum tipo de engajamento.

A vivência em hackerspace exige engajamento real, e isso é muito mais que apenas curtir a ideia ou os momentos presenciais. Engajamento é uma escolha do sujeito sobre si mesmo e essa escolha afeta ou influencia pessoas que estão em volta, nesse sentido, engajamento tem uma dimensão individual, comunitária e coletiva. A ideia de engajar-se em algo se contrapõe à pseudoparticipação (FREIRE, 1987) ${ }^{7}$ e se sobrepõe à participação apenas afetiva e instrumental (BORDENAVE,1989) ${ }^{8}$ e isso nos leva a 
defender processos de construção de autonomia, visto que a participação efetiva se constrói com a autonomia nos planos individual e coletivo. Aprendemos com hackerspaces que o engajamento é um tipo de participação que se dedica a colaborar para que outras pessoas se façam presentes, logo, todo engajamento exige algum tipo de participação mas nem toda participação é engajamento.

A partir dessa investigação, afirmamos que a manutenção e consolidação de hackerspaces, precisa considerar pelo menos quatro tipos engajamentos: a) Engajamento técnico: a presença em um hackerspace é motivada pelo interesse em praticar, desenvolver ou aprender mais sobre tecnologias, afinal, como seres técnicos, precisamos desenvolver técnicas para modificar a natureza de acordo com nossas necessidades e interesses. b) Engajamento afetivo: fundadores/as de hackerspaces o fizeram na companhia de amigos/as. É comum aos integrantes se vincularem pela relação de amizade e de sociabilidade. Mas a afetividade não se resume às relações interpessoais. A convivência em hackerspaces é uma relação teleoafetiva (BURTET, 2014) ${ }^{9}$ por relacionar diretamente às crenças, expectativas e desejos que orientam as ações individuais. Nesse sentido, o espírito lúdico que é descontraído e despreocupado (HUIZINGA, 2010, p.219) ${ }^{10}$, torna os espaços mais afetivamente interessantes. c) Engajamento ideário: pessoas de várias áreas tem se encantado com as potencialidades do "jeito hacker" principalmente quanto ao pensar diferente, livre e inovador. Além disso, o reconhecimento das contribuições históricas dos hackers a partir do trabalho colaborativo e apaixonado, no incentivo à circulação plena de ideias e descobertas, do livre acesso ao conhecimento e a intensificação da criação (PRETTO, 2010a; 2010b) ${ }^{11}$, produz uma visão dos hackerspaces como local necessário para experimentação e aprendizagem livres, local de subversão, de produção e compartilhamento de conhecimentos, de sociabilidade, de diversão. Em função disso, é comum encontrar pessoas que apoiam esses espaços, participam de suas redes e fazem doações mesmo sem nunca chegar a conhecê-los presencialmente. d) Engajamento ativista: o ativismo está no fazer atento às necessidades do espaço hacker mas também à divulgação de todo o movimento. $\mathrm{O}$ fazer preocupado com a realidade envolvente é encontrado em grupos hackers. Consequentemente o ativismo se dá no engajamento com a vida interna da sede através do desenvolvimento de ações que projetam a filosofia hacker e o próprio espaço para além de si mesmo, não bastando o ativismo apenas de rede social. É preciso "sair do sofá, levantar da cadeira” e se fazer presente fisicamente. A existência e manutenção de espaços autogestionários como hackerspaces depende de dois tipos de presença: no espaço físico e no ciberespaço uma vez que hackerspaces são locais de convergência para engajamento nessas duas frentes.

Fazer parte de um hackerspace pode ser prazeroso mas não é algo simples. Ao analisarmos alguns desafios apresentados por integrantes desses espaços, foram evidenciados alguns problemas e limitações que desestimulam a permanência nos grupos. São eles: a) Dispersão de pessoas: a falta de assiduidade nos encontros presenciais e lidar com pessoas que não se engajam nem se responsabilizam por atividades gera sobrecarga de responsabilidade e de trabalho para os poucos que se engajam. b) caráter voluntário da participação: por se tratar de um presença voluntária, é comum que os integrantes tenham outras prioridades, dispondo de pouco tempo para planejar os encontros temáticos, os projetos ou até, dar continuidade a eles; c) Dispersão de objetos: quando não há uma forma de organização de ferramentas e demais objetos da sede, as atividades e o ânimo do grupo são prejudicados pela desorganização; d) limitações infraestruturais e financeiras: prejudicam a manutenção da sede, e o desenvolvimento de projetos que exigem instrumentos ou materiais que não são conseguidos por doações. e) encontros pouco inclusivos: a inclusão não se resume aos aspectos de acessibilidade, ela também tem a ver com as relações pessoais e coletivas estabelecidas a cada encontro. Posturas preconceituosas, sexistas, pessoas que não querem compartilhar momentos e ideais, pessoas que agem com superioridade, respaldando-se em certificações, títulos acadêmicos ou diplomas para se posicionar perante os demais são vistas com enorme desconfiança. Quando situações de conflito se estabelecem nem sempre ocorre a mediação necessária para promover acolhimento podendo gerar afastamentos, desestímulos e ausências que colocam em risco o futuro do espaço. Pessoas que não compreendem a cultura daquele grupo, tendem a não se interessar. Essa inclusão é um passo importante para que as pessoas se sintam pertecentes ao grupo, contudo, não é suficiente, pois é necessário que seja construída e incentivada a autonomia 
das pessoas para assumir projetos e encampar ações em nome do grupo.

Diante disso, a relação entre educação e vida é muito forte, pois é desse processo de diálogo, acolhimento, inclusão, participação, engajamento que o hackerspace se mantém vivo.

\section{CONCLUSÕES}

A construção de engajamentos não se dá de forma natural dentre os integrantes de espaços hackers. Trata-se do resultado de interações entre os participantes, tanto quanto de um jogo complexos de subjetividades que determinam o sentido de ser e de estar em espaços como estes. Portanto, são fenêomenos relacionais e de tal modo, educativos, mesmo que aconteçam de forma intuitiva e não intencional entre os envolvidos.

Quando nos propusemos a investigar hackerspaces brasileiros desconfiávamos da existência de uma pedagogia hacker e buscamos sistematizar suas formas e seus princípios. Percebemos que não há separação entre a educação e a vida do espaço hacker, porque a existência dele depende dos processos educativos que ocorrem e nos quais ele se estrutura.

Os integrantes de hackerspaces se deparam com muitos desafios e cada desafio os leva a aprendizados: o primeiro aprendizado dos integrantes de um espaço hacker, por exemplo, é criar um local juntando pessoas e oportunidades que tornem isso viável. O segundo desafio é mantê-lo em funcionamento e para isso, é preciso aprender a compartilhar, para benefício coletivo.

A pedagogia hacker, nesse contexto, exige autonomia e compromisso mesmo diante de esvaziamento e solidão. Exigente de posturas ativas tanto dos aprendizes quanto dos mestres, requer resiliência às vezes e persistência, sempre. A convivência entre os integrantes precisa ser amalgamada no sentimento de pertença: cada pessoa se sente parte, faz parte e é reconhecida por isso essa é a convivência engajada que leva, através de suas práticas educativas, à partilha da cultura, dos valores e do local.

Como se vê o engajamento em hackerspaces não é um conceito genérico, mas um conjunto de engajamentos com inclinações e motivações específicas fortalecidas pela convivência e que se interconectam como faces de uma pirâmide: a pirâmide da pedagogia hacker (P2H). A base dessa pirâmide tem origem na motivação inicial do participante e mas não precisa ser uma base permanente, afinal,

Base é aquilo que estrutura, que mantém firme, e na pedagogia dos hackerspaces elas são perfeitamente cambiáveis. Uma pessoa que se aproxima do espaço interessada em conhecimento técnicos, tem na face técnica sua primeira base. Com a convivência partilhada, com a participação efetiva, essa pessoa pode desenvolver um forte engajamento ideário que a motiva a permanecer no espaço hacker e contribuir com ele de outras formas muito além das questões técnicas. Do mesmo modo, uma outra pessoa que vai ao hackerspace por motivação afetiva, seja para acompanhar um amigos ou um cônjuge, pode começar a se interessar pelos saberes técnicos e engajar-se por aí. (MENEZES, 2018:153-154)

A pirâmide da pedagogia hacker nos permite uma síntese para se refletir a educação de forma mais ampla, pois questões importantes se colocam quando aceitamos que para se educar é preciso, no mínimo, abarcar as afetividades, os ativismos, os ideários, e as técnicas.

Ao estudar as posturas de participantes engajados, notamos a busca pela autoformação pela criação de redes de pessoas, de prjetos, ou de saberes, e isso vai conectando ou reconectando indivíduos em torno de objetivos comuns, sem massacrar as individualidades. Quando um grupo de pessoas resolve se reunir para tornar realidade uma utopia de vida, está também materializando uma utopia educacional. A utopia é aqui assumida como uma recusa ao fatalismo, uma força para o agir acreditando no movimento humano de recriação do mundo e de si mesmo. Isso tem a ver com engajamento.

\section{REFERÊNCIAS}

[1] MENEZES, Karina Moreira. P2H: pirâmide da pedagogia hacker : [vivências do (in)possível] / Tese (doutorado em Educação) - Faculdade de Educação, Universidade Federal da Bahia. Salvador, 2018.

[2] CASTELLS, Manuel. O Informacionalismo e a Sociedade em Rede in HIMANEN, Pekka. A ética dos hackers e o espírito da era da informação. Rio de Janeiro: Campus, 2001.

[3] CAZELOTO, Edilson. Inclusão digital: uma visão crítica. São Paulo: Senac São Paulo, 2008. 208p.

[4] DIAMANTAS, Hernani. Zonas de colaboração: conversas da MetaReciclagem. Senac: São Paulo, 2013.

[5] CHARMAZ, Kathy. A construção da Teoria Fundamentada: Guia prático para a análise qualitativa. Joice Elias Costa (Trad.) Porto Alegre: Artmed, 2009. 272p.

[6] ASTERA. PETTIS, Bree. Hackerspaces The Beginning. 2008. 
Disponível em https://archive.org/details/hackerspaces-thebeginning

[7] FREIRE, Paulo. Pedagogia do Oprimido. Rio de Janeiro: Paz e Terra, 1987.

[8] BORDENAVE, Juan E. Diaz. O que é participação. São Paulo: Brasiliense, 1989.

[9] BURTET, Cecília Gehardt. Os saberes desenvolvidos nas praticas em um hackerspace de Porto Alegre. Dissertação Mestrado. Universidade Federal do Rio Grande do Sul,
Escola de Administração, Programa de Pós-graduação em Administração, Porto Alegre, 2014.

[10]HUIZINGA, Johan. Homo Ludens. João Paulo Monteiro (trad). São Paulo: Ed. Perspectiva, 2000.

[11] PRETTO, Nelson De Luca. Professores universitários em rede: um jeito hacker de ser. Editora Autêntica, 2010a. disponivel em http://repositorio.ufba.br/ri/handle/ri/1567; PRETTO, Nelson de Luca. Redes colaborativas, ética hacker e educação. Educ. rev. [online]. 2010, vol.26, n.3, pp. 305-316. 